\title{
FEM ANALYSIS OF MAIN PARTS OF A MANIPULATOR FOR MOUNTIG A COMPRESSOR TO A CAR EQUIPPED WITH A PNEUMATIC SUSPENSION SYSTEM
}

\author{
Miroslav BLATNICKÝ ${ }^{1}$, Ján DIŽO ${ }^{1}$, Dalibor BARTA ${ }^{1}$, Pawel DROŹDZIEL ${ }^{2}$ \\ ${ }^{1}$ University of Žilina, Faculty of Mechanical Engineering, Department of Transport and Handling Machines, \\ Univerzitná 8215/1, 01026 Žilina, Slovak Republic, miroslav.blatnicky@fstroj.uniza.sk, \\ jan.dizo@fstroj.uniza.sk, dalibor.barta@fstroj.uniza.sk \\ ${ }^{2}$ Lublin University of Technology, Faculty of Mechanical Engineering, Department of Transport, Combustion \\ Engines and Ecology, ul. Nadbystrzycka 36, 20-618 Lublin, Poland, p.drozdziel@ pollub.pl \\ Abstract \\ The article deals with a FEM analysis of main parts of an engineering design of a pneumatically \\ controlled manipulator, which will serve for mounting a compressor to a PO536 car chassis. This car chassis \\ belongs to SUV cars and it is equipped with a pneumatic suspension system. It is the chassis of a Porsche \\ Cayenne car produced in the Slovak Republic. The designed manipulator will be located on the assembly line \\ of this vehicle. Except of FEM analyses of designed important parts of the manipulator, which are necessary \\ for verification of safety of the design in order to obtain distribution of stresses and deformations in a \\ structure, the it contains also the design of a pneumatic circuit of the manipulator together with pneumatic \\ logic and it individual components. Based on three-dimensional model, there will be possible to generate \\ drawings of the manipulator for manufacturing of the device and its application to the real operation.
}

Keywords: engineering device, FEM simulations, pneumatic mechanism, vehicle

\section{INTRODUCTION}

Raising requirements about quality and quantity of products together with demands of large range of goods are conditioned by implementation of mechanisation and automatisation. More operators in production process lead to increasing of production, however better productivity and effectiveness is possible to reach just by application of means of mechanisation and automatisation. Recently, it is the only one way by reason that labour reserves are limited. Therefore, the request of a special device has arisen. The device will participate in improving of productivity and production of a manufacturing corporation in Slovakia.

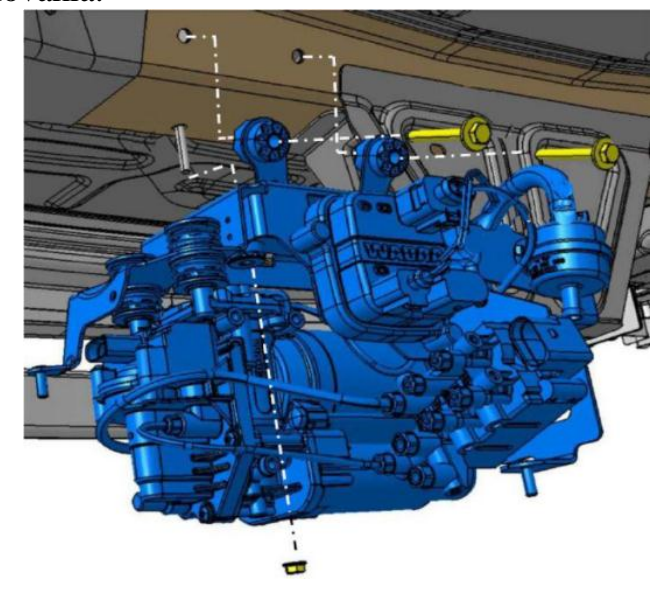

Fig. 1. A view of mounting a compressor to the car chassis
The objective of the solved problem is the production and installation of the device - the manipulator - which will serve for mounting an air compressor to the car chassis. A 3D model of the compressor and a part of a car chassis are shown in Fig. 1. The solved task has to meet all requirements insisted on the manipulator [2], theoretical principles of designing of the given mechanism and working principle as well as the engineering design itself [3] including all aspect of safety, ergonomics, sustainability, geometrical parameters [5, 13] and other requirements, which are demanded during assembly process of cars with pneumatic suspension system $[6,14]$ The very important part of the designed manipulator is a pneumatic brake.

\section{ENGINEERING DESIGN \\ OF A PNEUMATIC BRAKE \\ OF THE MANIPULATOR}

The required working principle of the pneumatic brake is depicted in Fig. 2. When the brake switch is activated, the manipulator has to be fixed in the $x$ direction. In this case, neither control element nor external effects can cause some movement of the manipulator, i. e. neither lifting nor rotating. Interlock of the manipulator in the $x$ direction is ensured by means of the pneumatic cylinder Festo DSBC-32-25-PA-N3, which prevents after activation the movement by a rubber part leaning against an aluminium profile. An 
adjustable pressure valve mineralizes an extensive loading of the manipulator structure.

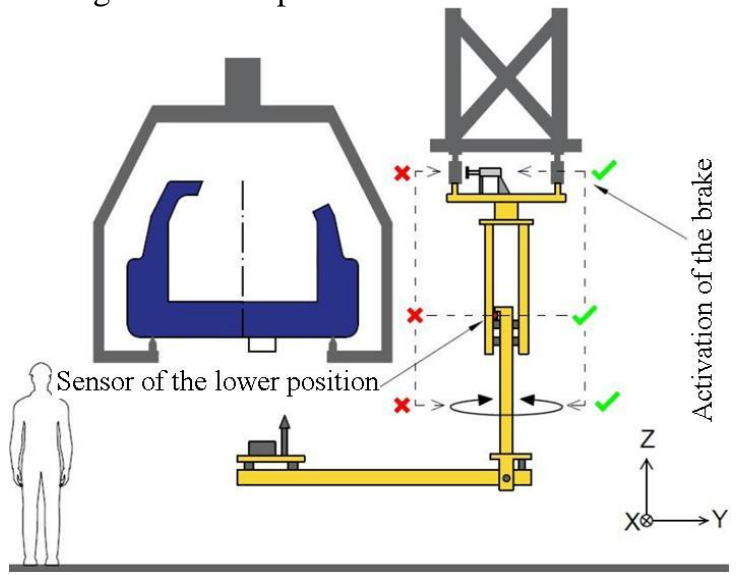

Fig. 2. A scheme of a working principle of the sensor of the lower position

It allows setting the needed pressure of the rubber part to the aluminium profile. Residual pressure in pneumatic cylinders and pneumatic reverse valves Festo HGL avoid moving the manipulator in vertical direction as well as in rotational direction because of external force effects or accidental using of control elements. When the brake is activated, compressed air is released from control elements and the given accidental command cannot be performed.

Another important factor in term of the brake design was prevention of the brake activation in improper position of the manipulator. It is ensured using the sensor of the lower position Festo R3-M5 (Fig. 2). It is needed to note, that all inputs of pneumatic cylinders are equipped with pneumatically controlled reversed valves Festo HGL. They insure the needed pressure in a cylinder despite of loss of pressure. It is important mainly for the lifting cylinder DSBC-50-800-PA-N3, which acts in the vertical direction $z$. In case of loss pressure, the arm could fall down because of its mass in the direction of the lower position and even it could injure operators. Moreover, these valves improve movement smoothness of individual cylinders. A model of the workplace is shown in Fig. 3.

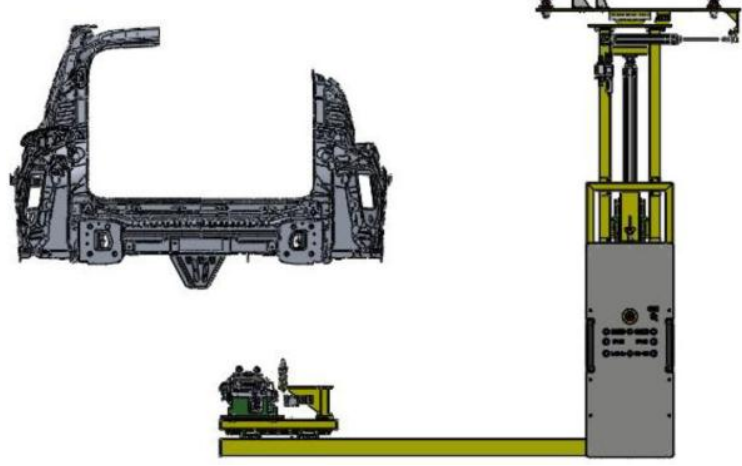

Fig. 3. A model of the created workplace

The used compressed air is treated by means of the compressed air treatment unit Festo MSB4-1/4C4-J2-WP. A scheme of the designed manipulator is depicted in Fig. 4.

\section{ANALYSES OF SELECTED COMPONENTS BY MEANS OF THE FINITE ELEMENT METHOD}

Strength analysis of selected parts of the designed device was subsequent step in designing of the manipulator for mounting an air compressor to a car chassis. It was carried out by means of Ansys software [7, 17] working based on the finite element method $[15,16,18,19]$ and these analyses

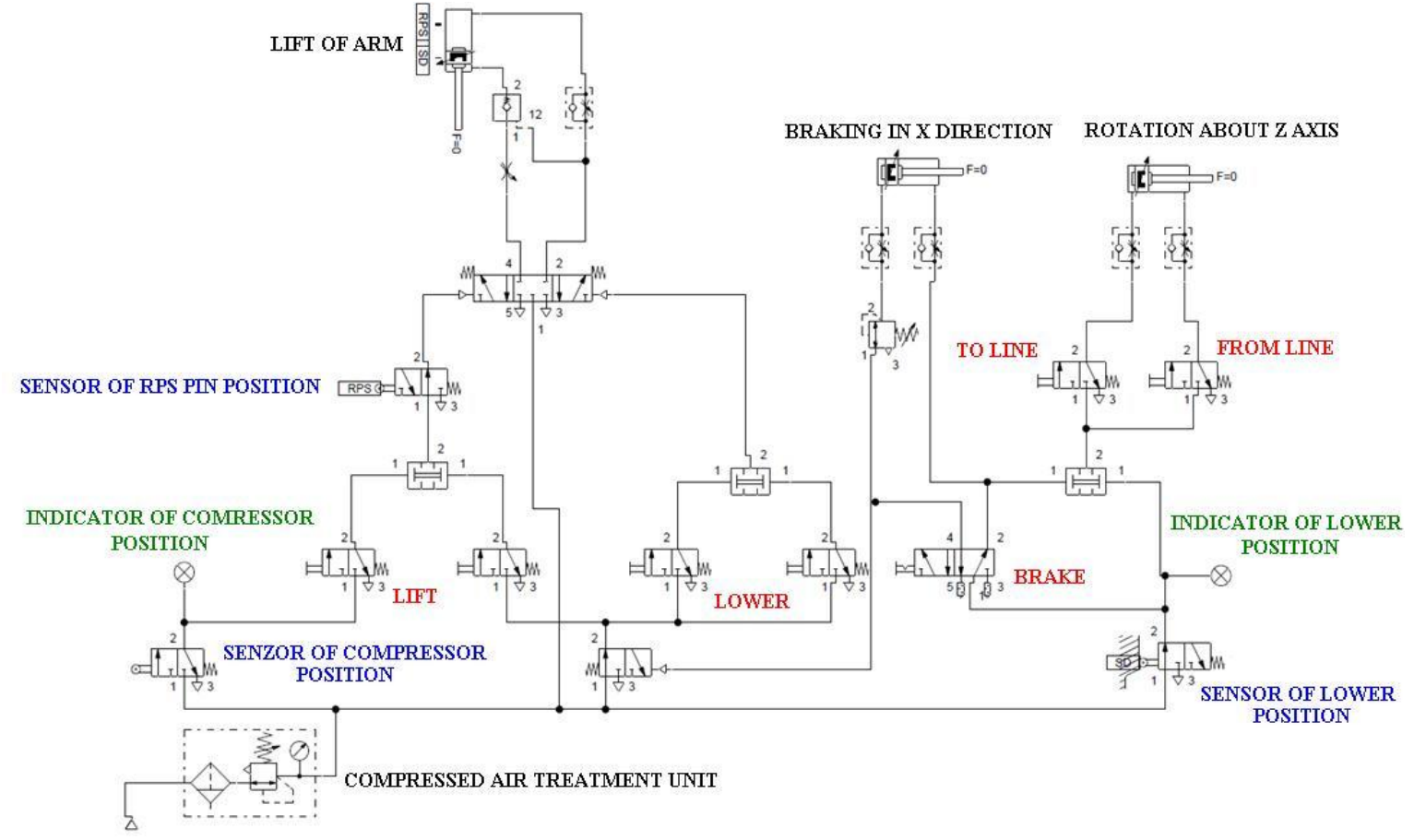

Fig. 4. A scheme of the designed pneumatic system 
are important to verify, weather the main carrying components meet all requirements in term of carrying capacity and integrity. Simulations were focused on obtaining of values of stresses and deformations after loading by real forces values. There were analysed following components:

- a steel plate carrying the manipulator,

- an adjusting mechanism,

- a console of a RPS pin.

\subsection{A steel plate}

During designing of the manipulator there was supposed, the steel plate carrying the whole weight of the manipulator will be one of the most loaded element. Therefore, the thickness of the plate has been chosen of $10 \mathrm{~mm}$ and it will be made of S235JR steel. Material properties are listed in Tab. 1.

Table 1. Properties of the S235JR steel

\begin{tabular}{|r|r|}
\hline & S235JR steel \\
\hline Density $\rho\left(\mathrm{kg} \cdot \mathrm{m}^{-3}\right)$ & 7,850 \\
\hline Poisson's coefficient $\mu(-)$ & 0.3 \\
\hline Young's module $E(\mathrm{MPa})$ & $210 \cdot 10^{3}$ \\
\hline Yield of strength $R_{e}(\mathrm{MPa})$ & 235 \\
\hline Ultimate strength $R_{m}(\mathrm{MPa})$ & 360 \\
\hline
\end{tabular}

For better accuracy of calculation, there was necessary to define all welded elements. Contact surfaces of welds and welded parts were defined by means of the "Connections" function. Welds and welded surfaces in contacts were defined using the "Bounded" function. It resulted to solid joints of selected elements. On the contrary, contacts between surfaces, which have been just in contact without welded joints, were defined as "Friction" function. It means that they behaved during calculation as surfaces with a friction contact $[1,4$, $12,19]$. In this case, it is a steel-steel contact. Boundary conditions have been chosen as following: a rotation coupling has been defined on four surfaces, in which the steel plate in connected with trolleys (Fig. 5). It allows rotating about all axes and also translation movement in the $x$ direction. The rotation coupling defines a joint coupling the trolley and the plate. The translation in the $x$ direction defines movement of the trolley on a rail.

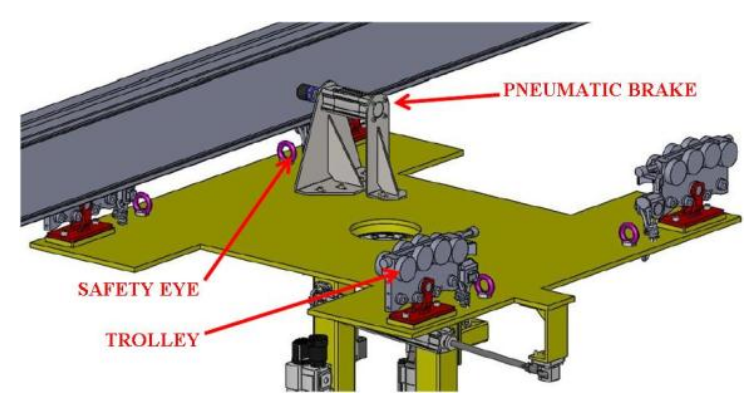

Fig. 5. A three-dimensional model of a trolley travel
The loading force acts on the mounting surface of a bearing in the vertical direction. Its value represents the gravitational force of the device hanging on the plate. The manipulator weight has been determined of $150 \mathrm{~kg}$. The loading force has been rounded on the value of 2,000 $\mathrm{N}$ taking into account the gravitational acceleration and the safety coefficient. Obviously, the effect of the device dead weight was taken into the calculation. Figure 6 shows a three-dimensional model of the designed manipulator and its location on the workplace.

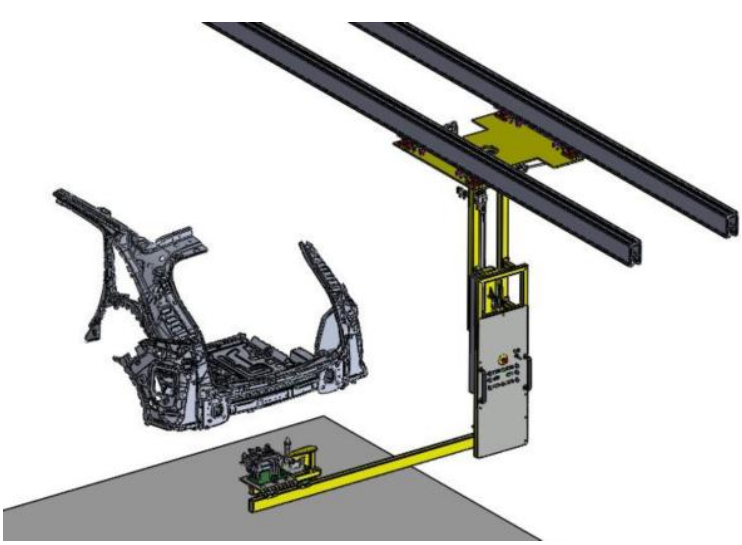

Fig. 6. A three-dimensional model of the designed manipulator and its location on the workplace

After definition of needed boundary conditions, parameters of FE mash and other parameters, the calculation has been performed. Results of stresses calculated in compliance with the von-Misses theory are shown in Fig. 7 and Fig. 8.

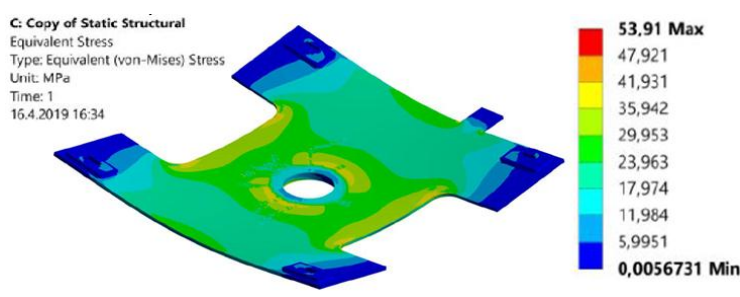

Fig. 7. Distribution of von-Misses stresses in the steel plate (3D view)

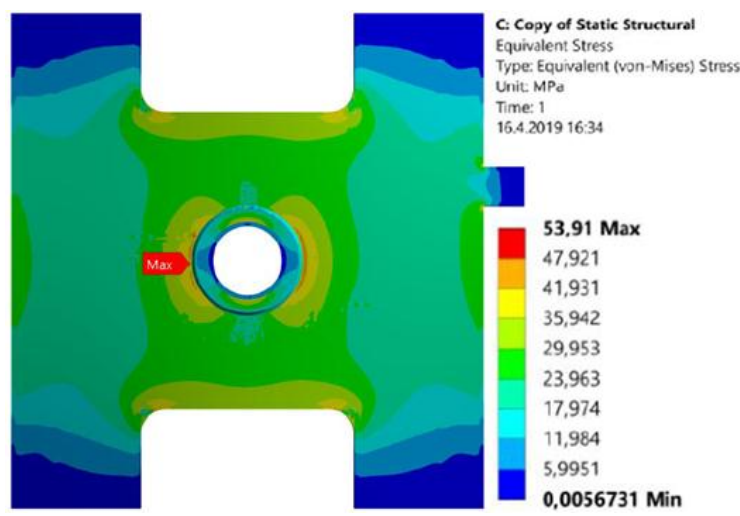

Fig. 8. Distribution of von-Misses stresses in the plate (2D view) 
From these figure we can conclude, that the maximal calculated value of the stress is of 53.91 MPa. It means that we have chosen the proper construction material as well as its utilization is optimal. Moreover, the safety in term of strength of the designed device is fulfilled.

As it was supposed, maximal values of stresses are reached in locations of welded joints, where they connect the working area of the bearing with the plate.

Stresses have greater values in plate edges. Just for this reason, edges are rounded. Despite of this fact, these locations show higher, however acceptable values of stresses. We suppose to verify visual check of these exposed welds during auditing inspections of the device.

The calculation of deformation has again confirmed the location of the supposed deflection of the steel, which is depicted in Fig. 9. Obtained maximal value of the plate deflection of $3.1 \mathrm{~mm}$ does not mean the engineering problem and it is acceptable.

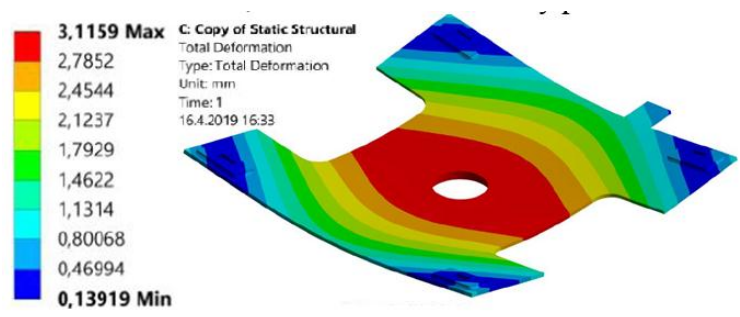

Fig. 9. Deformation of the plate under the determined load

Total deformation in the vertical direction is completely compensated by the lift of the pneumatic piston as well as by setting of end surfaces. Hence, the engineering design of the device has sufficient reserve for setting of the device with regard to these facts.

\subsection{An adjusting mechanism}

Other component, which has been the subject of FE analysis, an adjusting mechanism is (Fig. 10, Fig. 11). It contains a pin joint [3]. This calculation is in comparison with the previous one more difficult mainly in term of degrees of freedom, number of used materials, larger number of welds and contacts between individual components. It is composed from several types of materials.

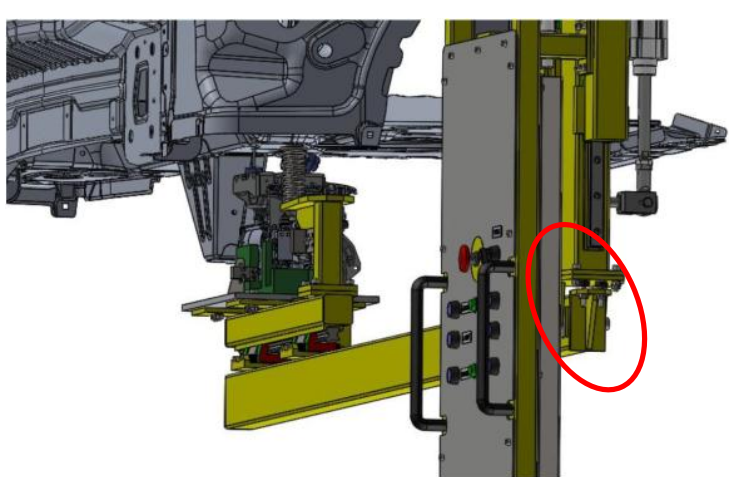

Fig. 10. A three-dimensional model of the manipulator with marking of the adjusting mechanism position

Welded parts are made of the structural steel S235JR by reason that it is suitable for welding and it has sufficient mechanical properties (Tab. 1). A pin of the adjusting mechanism is made of $\mathrm{C} 45 \mathrm{G}$ premium steel $\mathrm{C} 45 \mathrm{G}$, which important properties are introduced in Tab. 2.

Table 2. Properties of the premium steel C45G

\begin{tabular}{|r|r|}
\hline \multicolumn{2}{|c|}{ Premium steel C45G } \\
\hline Density $\rho\left(\mathrm{kg} \cdot \mathrm{m}^{-3}\right)$ & 7,700 \\
\hline Poisson's coefficient $\mu(-)$ & 0.3 \\
\hline Young's module $E(\mathrm{MPa})$ & $200 \cdot 10^{3}$ \\
\hline Yield of strength $R_{e}(\mathrm{MPa})$ & 550 \\
\hline Ultimate strength $R_{m}(\mathrm{MPa})$ & 880 \\
\hline
\end{tabular}

Adjusting screws compose two materials. The screw is made of the steel AISI 12L3 (Tab. 3) and the contact surface is made of polyoxymethylene, which is known as POM material (Tab. 4).

Table 3. Properties of the steel AISI 12L13

\begin{tabular}{|r|r|}
\hline & Steel S235JR \\
\hline Density $\rho\left(\mathrm{kg} \cdot \mathrm{m}^{-3}\right)$ & 7,870 \\
\hline Poisson's coefficient $\mu(-)$ & 0.29 \\
\hline Young's module $E(\mathrm{MPa})$ & $200 \cdot 10^{3}$ \\
\hline Yield of strength $R_{e}(\mathrm{MPa})$ & 235 \\
\hline Ultimate strength $R_{m}(\mathrm{MPa})$ & 395 \\
\hline
\end{tabular}

Table 4. Properties of polyoxymethylene

\begin{tabular}{|r|r|}
\hline & Polyoxymethylene \\
\hline & 1,420 \\
\hline Density $\rho\left(\mathrm{kg} \cdot \mathrm{m}^{-3}\right)$ & 0.35 \\
\hline Poisson's coefficient $\mu(-)$ & 3,000 \\
\hline Young's module $E(\mathrm{MPa})$ & 70 \\
\hline Yield of strength $R_{e}(\mathrm{MPa})$ & \\
\hline
\end{tabular}

For required accuracy, there was necessary to again define types of contact surfaces between individual elements, e. g. in the pin joint as well as in the contact of plastic surfaces of adjusting screws with the steel surface. 


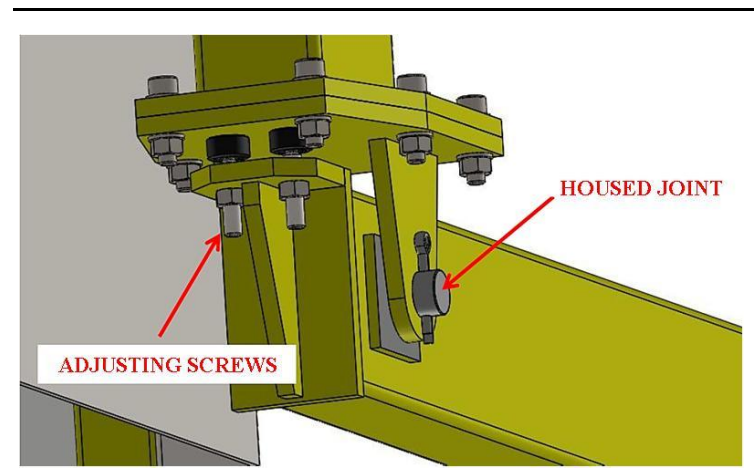

Fig. 11. A three-dimensional model of the adjusting mechanism

All contact surfaces of the pin were defined as friction surfaces [8-11]. Moreover, a contact between the adjusting screw and a bearing surface was defined as the friction contact. All welds were defined as "Bounded" elements and thus as the solid joint.

Boundary conditions were defined as following: the upper part of the adjusting mechanism (Fig. 11), from which a vertical guiding part of the manipulator arm continues, was defined as fixed joint. The dead weight of the device and the force representing the compressor gravity rounded to the value of $200 \mathrm{~N}$ have acted to the rest of the mechanism. The weight of this component is of $3.8 \mathrm{~kg}$. The given force will vary during operation of the mechanism just of the gravitational force value of the compressor, i. e. either it is present or not and that is of $50 \mathrm{~N}$. It is supposed, that the force will increase because of the stroke of the piston causing contact of the arm to the car chassis, whereas this stroke is limited by means of the RPS pin sensor.

Based on performed calculations and display their distributions (Fig. 12, Fig. 13) there is possible to found out, steel parts with holes for pins are the most loaded parts of the analysed component. From distributions we can see, that external edges are subjected to maximal tension stress of $88.44 \mathrm{MPa}$.

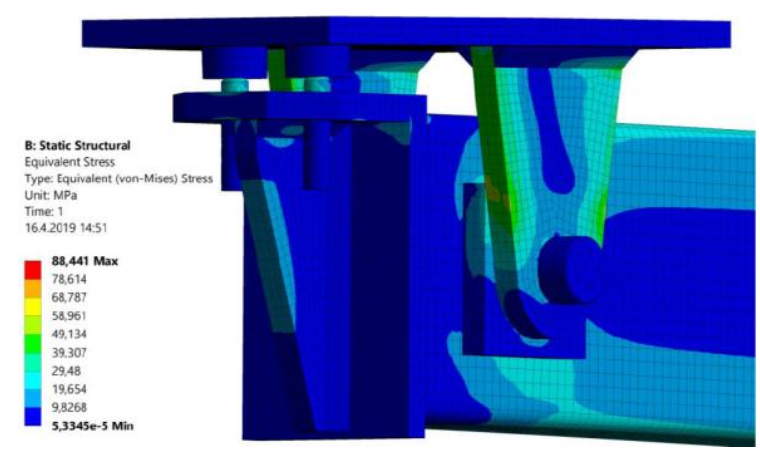

Fig. 12. Distribution of von-Misses stress in the adjusting mechanism (3D view)

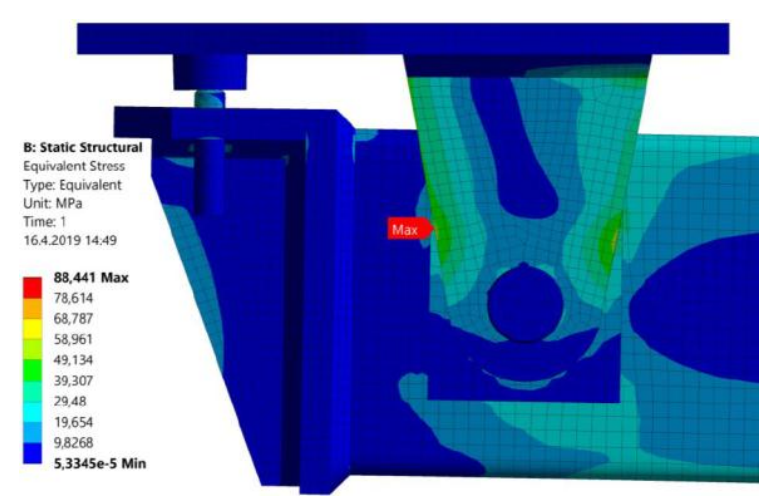

Fig. 13. Distribution of von-Misses stress in the adjusting mechanism (sidelight)

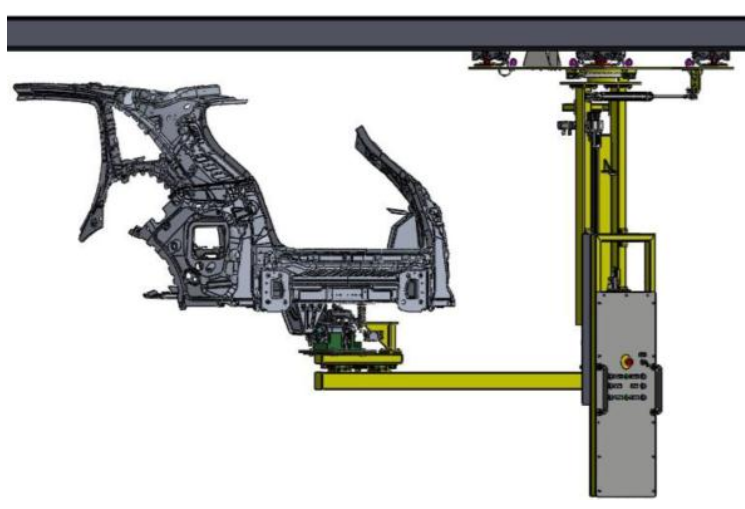

Fig. 14. A three-dimensional model of the designed manipulator during its operation in the workplace

As the yield of stress of the steel S235JR is of $235 \mathrm{MPa}$, it is possible to assume, that also in this case the requirements of safety will be fulfilled and during operation the material will not be damaged. However, there is recommended visually to verify the actual state of the component within auditing inspections (Fig. 14).

Besides results described above we have found out, that the shearing stress in the pin as well as pressure caused by adjusting screws are negligible.

\subsection{A console of a RPS pin}

The RPS pin (reference point system) is the only one element of the manipulator, which is in the contact with a car chassis during assembly of the compressor to the chassis. The force needed for pulling the manipulator along the assembly line is transmitted by the RPS pin and its console (Fig. 15). Therefore, it is necessary to analyse arose stress in these components. 


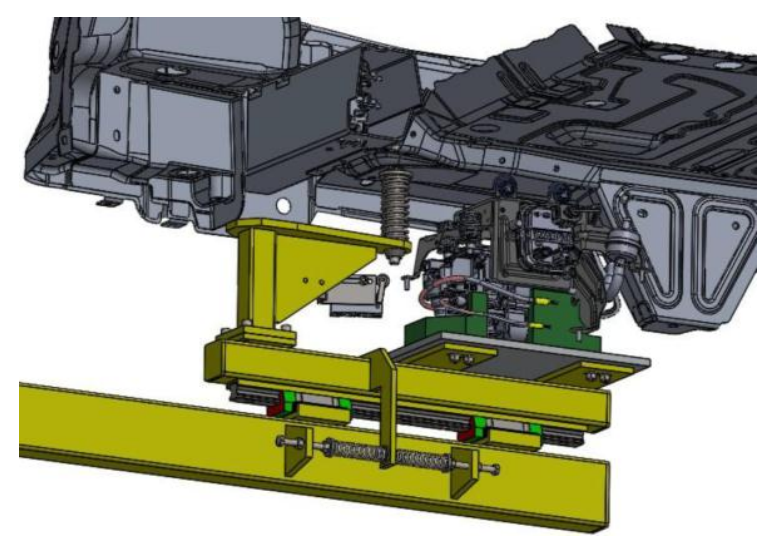

Fig. 15. A three-dimensional model of the console and the RPS pin during assembly

As well as in the previous cases, there was necessary to prescribed properties of individual contact surfaces. In this case, the friction contact and welded contact were supplemented by prescribing the screw joint behaviour. The friction of type steel-steel was defined between parts connected by the screw joint. The screw was divided into several surfaces. A surface touching down on a washer was defined as friction surface. A surface of an external thread of the screw was fixed with an internal thread of the lower connected part. A surface of the screw shank free-getting through the upper connected part was defined as a friction surface.

Table 5. Properties of a screw material

\begin{tabular}{|r|r|}
\hline \multicolumn{2}{|c|}{ Screw M8 DIN912 8.8} \\
\hline Density $\rho\left(\mathrm{kg} \cdot \mathrm{m}^{-3}\right)$ & 7,800 \\
\hline Poisson's coefficient $\mu(-)$ & 0.3 \\
\hline Young's module $E(\mathrm{MPa})$ & $200 \cdot 10^{3}$ \\
\hline Yield of strength $R_{e}(\mathrm{MPa})$ & 640 \\
\hline Ultimate strength $R_{m}(\mathrm{MPa})$ & 800 \\
\hline
\end{tabular}

In order to reach, that the screw joint will behave as a real joint, preload of the screw joint has to be defined. For the given screw DIN 912, strength category 8.8 and for the dimension of M8, the preload force is of $14.6 \mathrm{kN}$. Further, all important properties have to be input into the software. The whole structure except of the RPS pin is made of steel S235JR (Tab. 1). The RPS pin is made of steel C45G. It is premium steel (Tab. 2). Screws M8 DIN 9128.8 have strength parameters introduced in Tab. 5.

Finally, values of acting forces have to be determined. The force, which introduces the manipulator in uniform motion, is calculated and rounded to the value of $400 \mathrm{~N}$. The other force, which is just theoretical, was used for verifying. It is the maximal force, which is produced by the pneumatic piston just in case of RPS pin failure. In such a case, the arm could be pulled by the piston force in the direction against the car chassis. There was necessary to detect, if critical stresses in RPS console are not exceeded.
When the manipulator is loaded by the force needed for its actuation, the greatest stresses are generated just in the screw joint.

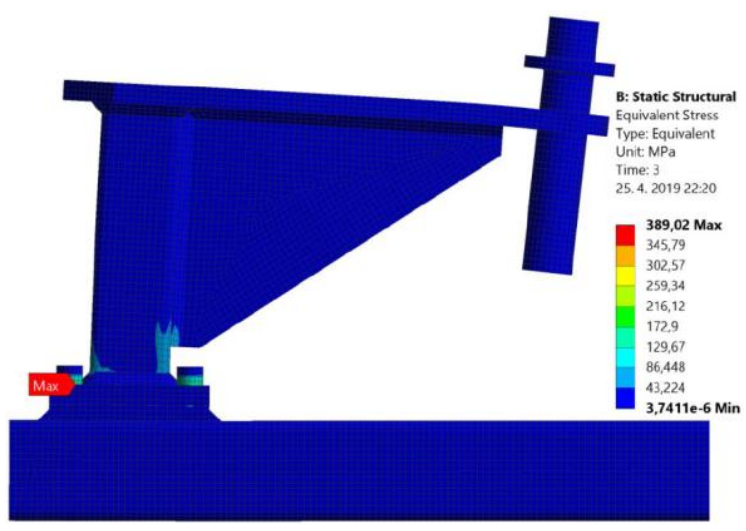

Fig. 17. Distribution of stress in the console caused by the pneumatic piston force
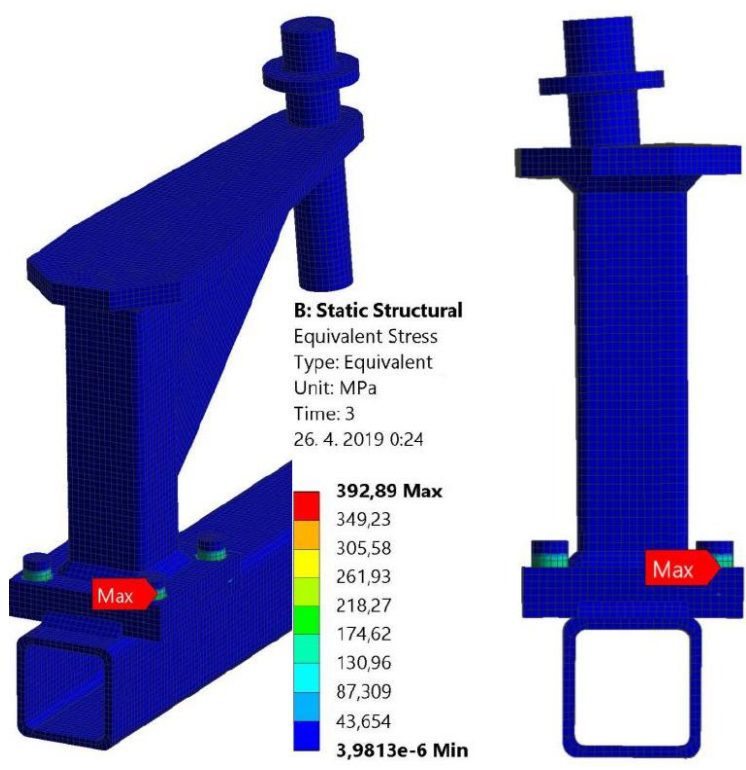

Fig. 16. Distribution of stress during manual pulling of the manipulator

The preloaded screw joint causes in the screw the stress of $386 \mathrm{MPa}$. As it can be identify (Fig. 16, Fig. 17), neither the structure of the console nor welds are too loaded under the considered force and thus, no part of the analysed components is critical loaded.

If the analysed structure is loaded by the force produced by the pneumatic piston, distribution of stresses in the structure is not different significantly (Fig. 17). Extreme values of stresses are again in preloaded screw joints. In comparison with the previous simulation values of stresses are even lower despite of the loading force is of $1,178 \mathrm{~N}$. This difference is caused by the resultant directional vector of the loading force. In the first analysed case, the loading force tends to bend and to crinkle the whole console structure, whereby the screw joint is multiaxially loaded. In the second analysed case, the bending load is dominant; 
therefore, the screw joint is loaded uniaxially, i. e. by the tension stress.

\section{CONCLUSION}

The practical part of the presented problem is based on obtained input data, i. e. requirements, which are demanded from the manipulator in the location of its final position. After studying and consultations, a structural and functional solution was created. The challenge was to design the bearing part of a compressor in compliance with all needed assembly dimensions together with possibility to compensate all inaccuracies. Moreover, there was necessary to take into account factors of safety, health protection and ergonomic parameters. Obviously, all standards and internal regulations of a customer have to be met. Selection of suitable and customers required components from particular providers were another important aspect. There are pneumatic components, control elements, hand-grips, electric components, linear guidance, rail systems etc. The engineering design of the manipulator has to consider not only mechanical functionality of the device, but also positioning of individual pneumatic components. It includes pneumatic cylinders, valves, control buttons, a compressed air treatment unit and other components needed for proper function of the pneumatic system. Except for positioning of individual elements, there was necessary to propose the working principle of the whole pneumatic system including pneumatic control. It contains all pneumatic components and pneumatic logic. These efforts have resulted to the functional threedimensional model of the device. Last but not least, there were performed numerical analyses of selected components of the device by means of the FEM in term of stress distribution. Numerical calculations have confirmed that analysed components meet all safety requirements. A threedimensional model of the functional, pneumatic controlled device is the general result of the solved problem. The model is verified by the FE software and after creation of production drawings, the device can be produced and set into operation.

\section{SOURCE OF FUNDING}

This work was supported by the Cultural and Educational Grant Agency of the Ministry of Education of the Slovak Republic in the project No. KEGA 023ŽU-4/2020: Development of advanced virtual models for studying and investigation of transport means operation characteristics.

\section{REFERENCES}

1. Askerov H, Vakulenko I, Grischenko N. Insights into factors of damage of surface rolling of railway wheels during operation. Scientific Journal of Silesiann University of Technology. Series Transport
$2019 ; 105$.

https://doi.org/10.20858/sjsutst.2019.105.3.

2. Blatnický M, Dižo J, Barta D, Drozdziel P. Streamlining assembly of a compressor to a car chassis with an air suspension system. Proceedings of $24^{\text {th }}$ International Scientific Conference. Transport Means 2020. To be published.

3. Blatnický M, Dižo J, Barta D, Rybicka I. Engineering design of a manipulator for mounting the air suspension compressor to a car chassis. Scientific Journal of Silesian University of Technology. Series Transport 2020. To be published.

4. Brunetti J, D'Ambrogio W, Fregolent A. Dynamic coupling of substructures with sliding friction interfaces. Mechanical Systems and Signal Processing 2020; 0141.

https://doi.org10.1016/j.ymssp.2020.106731.

5. Corejova T, Imriskova E. Convergence at the Postal Market. Eksploatacja i Niezawodność-Maintenance and Reliability 2008; 1(3): 74-76.

6. Czech P, Turoń K, Barcik J. Autonomous vehicles: Basic issues. Scientific Journal of Silesian University of Technology. Series Transport 2018 2018; 100. https://doi.org/10.20858/sjsutst.2018.100.2.

7. Fomin O, Gerlici J, Lovskaya A, Kravchenko K, Prokopenko P, Fomina A, Hauser V. Research of the strength of the bearing structure of the flat wagon body from round pipes during transportation of the railway ferry. MATEC Web of Conferences 2018; 235.

https://doi.org10.1051/matecconf/201823500003.

8. Izvolt L, Harusinec J, Smalo M. Optimisation of transition areas between ballastless track and ballasted track in the area of the tunnel Turecky vrch. Communications - Scientici Letters of the University of Zilina 2018; 20(3): 67-76.

9. Kul'ka J, Mantič M, Kopas M, Falitová E, Hrabovský L. Simulation-expertise analysis of ropes used in the horizontal belaying system. Scientific Journal of Silesian University of Technology. Series Transport 2019; 103.

https://doi.org/10.20858/sjsutst.2019.103.5.

10. Lack T, Gerlici J. Contact area and normal stress determination on railway wheel/rail contact. Komunikacie 2005; 7(2): 38-45.

11. Lack T, Gerlici J. Wheel/rail contact stress evaluation by means of the modified strip method. Komunikacie 2013; 15(3): 126-132.

12. Liu S, Song $\mathrm{C}$, Zhu $\mathrm{C}$, Liang $\mathrm{C}$, Bai H. Investigation on contact and bending stress of face-hobbed and face-milled hypoid gear. Mechanism and Machine Theory 2020;150. https://doi.org10.1016/j.mechmachtheory.2020.103873.

13. Parmová J, Urban L. Ergonomic intervention at the assembly line of the Skoda Roomster car. Ceske Pracovni Lekarstvi 2008; 9(4): 121-124.

14. Shalabi ME, El-Hussieny H, Abouelsoud AA, Fath Elbab AMR. Control of automotive air-spring suspension system using Z-number based fuzzy system. IEEE International Conference on Robotics and Biomimetics "ROBIO 2019": 1306-1311. Dali, China. 2019;6-8. https://doi.org10.1109/ROBIO49542.2019.8961492.

15. Smetanka L, Gerlici J, Lack T, Pelagic Z. Homogenization of fibres reinforced composite materials for simulation analysis. Manufacturing Technology 2015; 15(4): 914-920. 
16. Stastniak P, Harusinec J. Computer aided simulation analysis for coputation of modal analysis of the freight wagon. Komunikacie 2013; 15(4): 73-79.

17. Suchánek A, Harušinec J. The downhill braked railway wheel structural analysis by means of the ANSYS multiphysics program system package. Manufacturing Technology 2015; 15(5): 945-950.

18. Wierzbicki S. Diagnosing microprocessor controlled systems. Polska Akademia Nauk, Teka Komisji Motoryzacji i Energetyki Rolnictwa, Tom VI, Lublin, 200: 183-188.

19. Žmindák M, Pelagić Z, Pastorek P, Močilan M, Vybošt'ok M. Finite element modelling of high velocity impact on plate structures. Procedia Engineering 2016; 136: 162-168.

https://doi.org/10.1016/j.proeng.2016.01.191.

Received 2020-02-15

Accepted 2020-05-15

Available online 2020-05-20

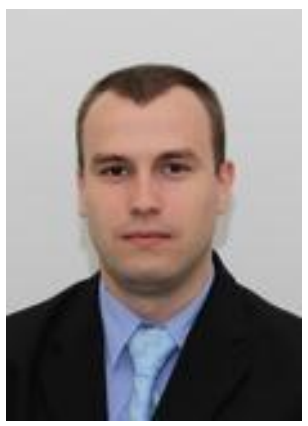

Ing. Miroslav BLATNICKÝ, $\mathrm{PhD}$. received M.Sc. and $\mathrm{PhD}$. degrees in Mechanical Engineering from University of Žilina, respectively. $\mathrm{He}$ is currently teaching at the Faculty of Mechanical Engineering, University of Žilina. His area of research is focused on functional and strength calculations and FEM analyses in the field of transport and handling machines, hoisting machinery and steel structures.

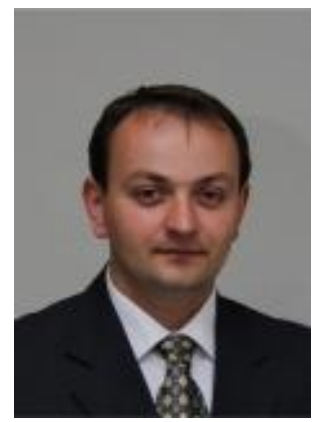

Ing. Ján DIŽO, $\mathrm{PhD}$. received B.Sc., M.Sc. and PhD. degrees in Mechanical Engineering from University of Žilina, respectively. $\mathrm{He}$ is currently teaching at the Faculty of Mechanical Engineering, University of Žilina. Mr. Dižo's research interest mainly focuses on creation of MBS models and analysing dynamic structural properties of transport and handling machines.

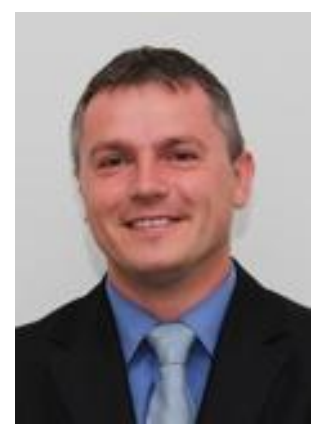

Doc. Ing. Dalibor BARTA, PhD. is the university professor at the Department of Transport and Handling Machines of Faculty of Mechanical Engineering of University of Žilina. His scientific fields of interest relate to the simulation and design of nonconvention drives of vehicles and using of alternative drives based on the real operating conditions.

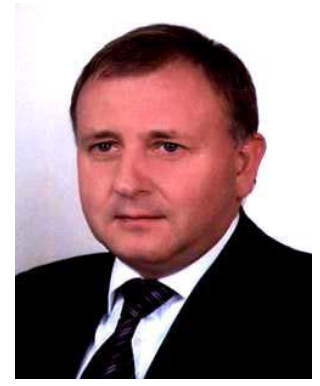

Dr. hab. inż Pawel DROŹDIEL, prof. PL works at the Institute of Transport, Combustion Engines and Ecology of Faculty of Mechanical Engineering of Lublin University of Technology, Vice-Rector of this university. Prof. Droźdiel focuses his research activities mainly on solving problems in the field of tribology, durability and safety technical systems. 